\title{
SCIENTOMETRIC ANALYSIS OF ASIAN COUNTRIES LIBRARY AND INFORMATION SCIENCE PUBLICATIONS
}

\author{
Senthilkumar, $\mathbf{R}^{\mathbf{1}^{*}}$. and G. Ulaganathan ${ }^{2}$ \\ ${ }^{1}$ Department of Library and Information Science, Kongunadu Arts \& Science College (Autonomous), \\ Coimbatore-641 029. Tamil Nadu, India. \\ ${ }^{2}$ Librarian, Dr. SNS.Rajalakshmi College of Arts \& Science, Coimbatore - 641 049, Tamil Nadu, India.
}

\begin{abstract}
This paper discusses about the Asian countries Library and Information Science publications during the period of 1996-2016 and its citation available in the Scimago Journal and Country Rank data base by the authors from top 15 countries (based on publications). The relevant data are collected from Scimago Journal and Country Rank data base and it was analyzed. It shows among the Asian countries Library and Information Science publications totally 21233 articles were published which are indexed in Scimago database. Among the publications, maximum of 8506(40.06\%) articles published by China and followed by Taiwan with $2764(13.02 \%)$ publications and India is in $3^{\text {rd }}$ place with $2626(12.37 \%)$ publications during the study period.
\end{abstract}

Keywords: Asian Countries, Library and Information Science, Scimago Journal and Country Rank, Citations, Self Citations, Citable Documents, H- Index.

\section{INTRODUCTION}

The true measurement of assessing the quality and quantity of a journal is the Citation Index. While discussing citation, one needs to know the citation. Simply, when another refers other works in his/her article, we describe the article referred is cited. In other words the citation is called as the earlier work which is referred in the present work. The quality of a given work can precisely be deemed through the number of citations that it gets. Therefore, a firm piece of article or research paper is carrying more number of citations get more impact than the work carrying less citation. Therefore, we always refer to some indexing and abstracting databases like Web of Science, Scopus, or even Google Scholars to know the impact of a particular journal, a article or a particular author. Scimago Journal and Country Rank database developed by Scimago Lab and powered by Scopus

\section{REVIEWOFLITERATURE}

Senthilkumar.R. et al. (1) this study analyzes the Astrophysics research output in India from 1989 to 2014. The study revealed that the highest number of publications is in the year 2013 with 913 records having a GCS of 4342 and LCS of 324. The major source of publication in Astrophysics research comes in the form of articles. Rajneesh et al. (2) have analyzed research output of Computer Science Literature, articles published in the "Journal of the ACM", for ten years in from 1999 to 2008 . The study envisages that a total number of 336 papers comprise of 10799 citations. The highest average citations per article were 37.25 the overall average of the citations per article is 32.14. Journals and conference proceedings and both of them together have shared $77 \%$ of the total citations. 3926 (36.88\%) citations authored by a single author, whereas 6719 citations (63.12\%) were multiple authors. It is evident that Computer science is one of the emerging disciplines. Krishnan et al. (3) have the Current science Publications research output, for the period of 2000 to 2013. Among 2357 records, the most productive author was Aswal V. K with 108 papers and the highest number of records 334 published in 2011 and 322 records in the year 2010. Total $73.8 \%$ of the literature was published records were articles. India was the top produced country with 1363 publications (57.8\%) followed by USA with 293 publications (12.4\%). Most productive Institution was Bhabha Atomic Research Center (BARC), which topped with 143 publications. Seeman et al. (4) have analyzed the growth rate of environmental science literature output in nineteen Universities of South India the period of $2000-2012$ were retrieved from Web of Science database Among total 6784 journal articles, the highest output was in the year 2012 that accounts for $13.97 \%$ and the 7694 journal articles occupy predominant position sharing $88.17 \%$ of total research output. A core set of 38 journals has covered about one third of the total publications made by the environmental science researchers in selected universities from South

*Correspondence: Senthilkumar, R., Department of Library and Information Science, Kongunadu Arts \& Science College 
India. Khatun et al. (5) have examined the periodical articles on diarrheal disease research in Bangladesh. The articles were derived from PubMed, Web of Science and Scopus databases from the period of 1971 to 2009 (38 Years). The total number of retrieved records was 1.521 ( PubMed 488; WoS 419; and Scopus 614). The unique 711 records were retained for analysis. The literature growth increased with an average 18.23 articles published per year. The majority of journals 99 (65.55\%) were published in the USA and UK.

\section{METHODOLOGY}

This study aims to discuss about the Asian countries Library and Information Science publications and its citation available in the Scimago Journal and Country Rank data base (6) by the top 15 countries (based on publications). The relevant data are collected from Scimago Journal and Country Rank database. Based on the available sources, the following discussions are made.

\section{ANALYSIS AND INTERPRETATION:}

The distributions of the Asian countries Library and Information Science publications by the top 15 countries that is available in Scimago Journal and Country Rank data base which were analyzed in the table 1.

\section{ASIAN COUNTRIES LIBRARY AND INFORMATION SCIENCE PUBLICATIONS (TOP 15 COUNTRIES)}

Table 1. Asian Countries Library and Information Science Publications (Top 15 Countries)

\begin{tabular}{cccc}
\hline S.NO & Country & $\begin{array}{c}\text { Library \& } \\
\text { Information } \\
\text { Science } \\
\text { Publication }\end{array}$ & \% \\
\hline 1 & China & 8506 & 40.06 \\
2 & Taiwan & 2764 & 13.02 \\
3 & India & 2626 & 12.37 \\
4 & Japan & 1674 & 7.88 \\
5 & South Korea & 1594 & 7.51 \\
6 & Singapore & 1253 & 5.90 \\
7 & Hong Kong & 994 & 4.68 \\
8 & Malaysia & 790 & 3.72 \\
9 & Pakistan & 416 & 1.96 \\
10 & Thailand & 255 & 1.20 \\
11 & Bangladesh & 141 & 0.66 \\
12 & Indonesia & 66 & 0.31 \\
13 & Sri Lanka & 64 & 0.30 \\
14 & Viet Nam & 51 & 0.24
\end{tabular}

\begin{tabular}{|c|c|c|c|}
\hline 15 & Philippines & 39 & 0.19 \\
\hline & Total & 21233 & 100 \\
\hline
\end{tabular}

The above Table shows that the countrywise distribution of Asian Countries Library and Information Science Publications From 1996 to 2016, totally 21233 articles were published which are indexed in Scimago database. Among the publications, maximum of $8506(40.06 \%)$ articles published by China and followed by Taiwan with $2764(13.02 \%)$ publications and India is in $3^{\text {rd }}$ place with $2626(12.37 \%)$ publications.

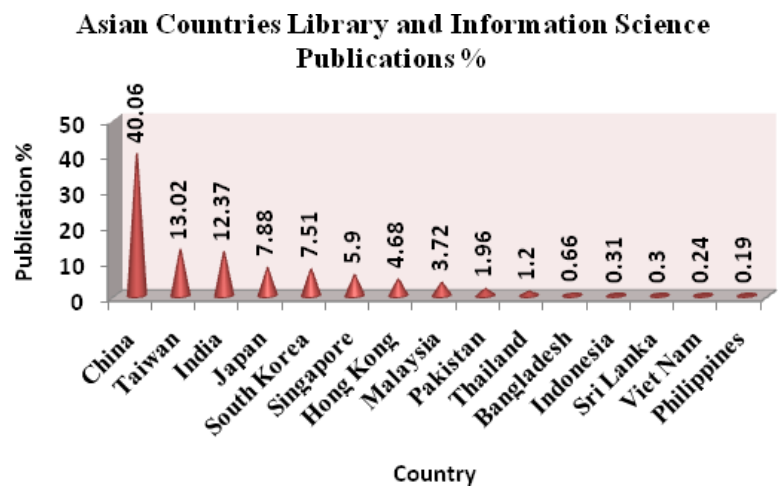

\section{ASIAN COUNTRIES LIBRARY AND INFORMATION SCIENCE CITABLE DOCUMENTS}

Table 2. Asian Countries Library and Information Science Citable Documents

\begin{tabular}{cccc}
\hline S.NO & Country & $\begin{array}{c}\text { Library\& } \\
\text { Information } \\
\text { Science Citable } \\
\text { Documents }\end{array}$ & \% \\
\hline 1 & China & 8422 & 40.45 \\
2 & Taiwan & 2722 & 13.07 \\
3 & India & 2566 & 12.32 \\
4 & Japan & 1581 & 7.59 \\
5 & South Korea & 1562 & 7.50 \\
6 & Singapore & 1209 & 5.81 \\
7 & Hong Kong & 969 & 4.65 \\
8 & Malaysia & 778 & 3.74 \\
9 & Pakistan & 409 & 1.97 \\
10 & Thailand & 245 & 1.18 \\
11 & Bangladesh & 141 & 0.68 \\
12 & Indonesia & 65 & 0.31 \\
13 & Sri Lanka & 63 & 0.30 \\
14 & Viet Nam & 50 & 0.24 \\
15 & Philippines & 39 & 0.19 \\
\hline & Total & 20821 & 100 \\
\hline
\end{tabular}

The above Table presents the countrywise distribution of Asian Countries Library and Information Science citable documents (includes 
articles, reviews and conferences papers), from top 15 countries from 1996 to 2016, 20821 citable documents were available which are indexed in Scimago database. Among the citable documents maximum of $8422(40.45 \%)$ by China followed by Taiwan with 2722(13.07\%) and India contributed 2566(12.32\%) citable documents.

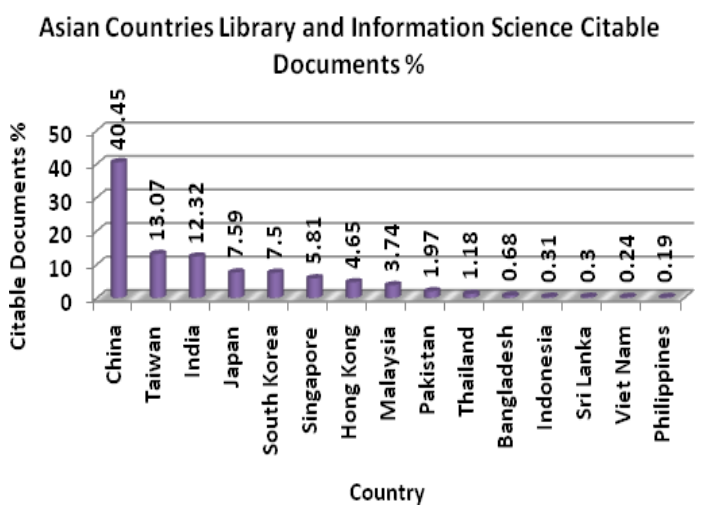

ASIAN COUNTRIES LIBRARY AND

INFORMATION SCIENCE CITATIONS:

Table 3: Asian Countries Library and Information Science Citations

\begin{tabular}{cccc}
\hline S.No & Country & $\begin{array}{c}\text { Library \& } \\
\text { Information } \\
\text { Science } \\
\text { Citations }\end{array}$ & \% \\
\hline 1 & China & 38816 & 23.99 \\
2 & Taiwan & 23967 & 14.81 \\
3 & India & 17028 & 10.52 \\
4 & Japan & 15346 & 9.48 \\
5 & South Korea & 16733 & 10.34 \\
6 & Singapore & 17726 & 10.95 \\
7 & Hong Kong & 22597 & 13.97 \\
8 & Malaysia & 4607 & 2.85 \\
9 & Pakistan & 1643 & 1.02 \\
10 & Thailand & 1884 & 1.17 \\
11 & Bangladesh & 656 & 0.41 \\
12 & Indonesia & 273 & 0.17 \\
13 & Sri Lanka & 221 & 0.14 \\
14 & Viet Nam & 187 & 0.12 \\
15 & Philippines & 102 & 0.06 \\
\hline
\end{tabular}

\section{ASIAN COUNTRIES LIBRARY AND INFORMATION SCIENCE SELF CITATIONS:}

Table 4: Asian Countries Library and Information Science Self Citations

\section{Library\&}

S.No. $\begin{gathered}\text { Country Information } \\ \text { Asian Countries Library and Information Science }\end{gathered}$
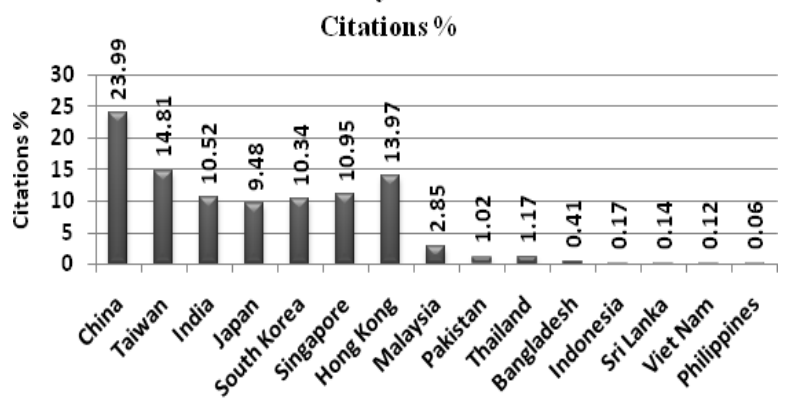

Country

Science Selt

\begin{tabular}{cccc}
\multicolumn{3}{c}{ Citations } \\
\hline 1 & China & 18336 & 44.76 \\
2 & Taiwan & 5504 & 13.43 \\
3 & India & 4408 & 10.76 \\
4 & Japan & 3649 & 8.91 \\
5 & South Korea & 2937 & 7.17 \\
6 & Singapore & 1785 & 4.36 \\
7 & Hong Kong & 1992 & 4.86 \\
8 & Malaysia & 1332 & 3.25 \\
9 & Pakistan & 583786 & 1400 \\
\hline 10 & Thailand & 217 & 0.53
\end{tabular}

11 bavgldabla shows the distribution of 0.30

Assian Colmetrifesialibrary and38nformation 0.8 gience

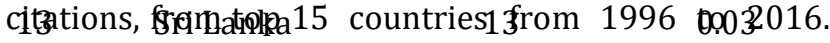
Alpong thiettitions maximum5of $38816(23.0 .9 \%)$ by China followed by Taiwan with 23967(14.81\%) and India contributed 17028(10.52\%) Citations. 
Philippines

Total
0.03

100

Asian Countries Library and Information Science Self Citations \%

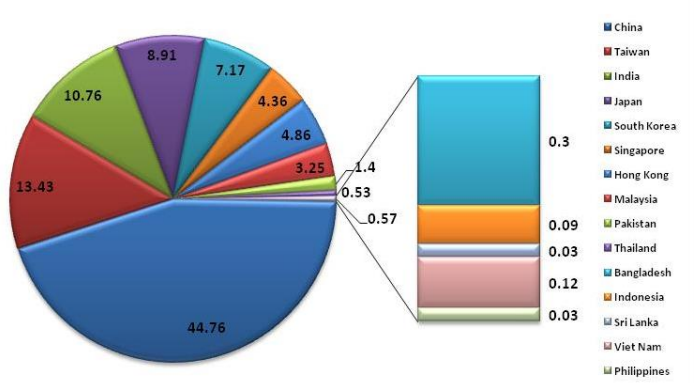


The above Table reveals the distribution of Asian Countries Library and Information Science self citations, from top 15 countries from 1996 to 2016. Among the Asian Countries Library and Information Science self citations maximum of $18336(44.76 \%)$ by China followed by Taiwan with $5504(13.43 \%)$ and India's self citation is 4408(10.76\%).

RANKING OF ASIAN COUNTRIES LIBRARY AND INFORMATION SCIENCE CITATIONS PER DOCUMENT:

Table 5: Ranking of Asian Countries Library and Information Science Citations Per Document

\begin{tabular}{cccc}
\hline S.NO & Country & $\begin{array}{c}\text { Citations } \\
\text { Per } \\
\text { Document }\end{array}$ & Ranking \\
\hline 1 & China & 4.56 & X \\
2 & Taiwan & 8.67 & V \\
3 & India & 6.48 & VII \\
4 & Japan & 9.17 & IV \\
5 & South Korea & 10.5 & III \\
6 & Singapore & 14.15 & II \\
7 & Hong Kong & 22.73 & I \\
8 & Malaysia & 5.83 & VIII \\
9 & Pakistan & 3.95 & XII \\
10 & Thailand & 7.39 & VI \\
11 & Bangladesh & 4.65 & IX \\
12 & Indonesia & 4.14 & XI \\
13 & Sri Lanka & 3.45 & XIV \\
14 & Viet Nam & 3.67 & XIII \\
15 & Philippines & 2.62 & XV \\
\hline
\end{tabular}

The above Table depicts that the ranking of Asian Countries Library and Information Science Citations per Document (Average citations to documents published during 1996-2016), from top 15 countries. Among the Ranking of citations per document study Hong Kong is in first rank with 22.73 followed by Singapore with 14.15 in second rank and South Korea is in third rank with 10.50 citations per document used.

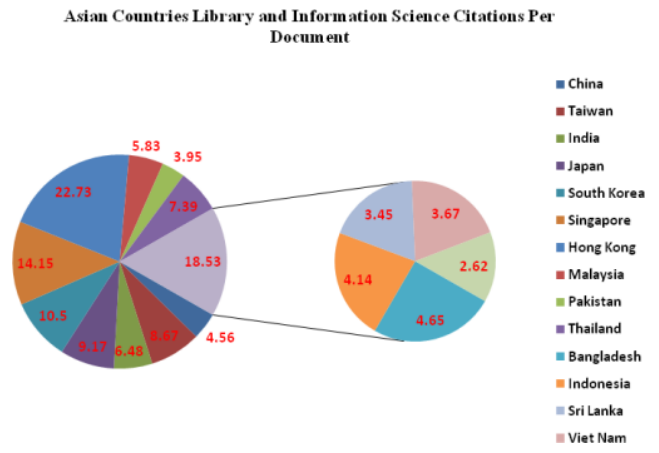

\section{RANKING OF ASIAN COUNTRIES LIBRARY AND INFORMATION SCIENCE H INDEX:}

Table 6: Ranking of Asian Countries Library and Information Science H Index

\begin{tabular}{cccc}
\hline S.NO & Country & H Index & Ranking \\
\hline 1 & China & 67 & I \\
2 & Taiwan & 62 & II \\
3 & India & 53 & V \\
4 & Japan & 55 & IV \\
5 & South Korea & 55 & IV \\
6 & Singapore & 60 & III \\
7 & Hong Kong & 62 & II \\
8 & Malaysia & 27 & VI \\
9 & Pakistan & 18 & VIII \\
10 & Thailand & 23 & VII \\
11 & Bangladesh & 15 & IX \\
12 & Indonesia & 8 & X \\
13 & Sri Lanka & 7 & XI \\
14 & Viet Nam & 7 & XI \\
15 & Philippines & 5 & XII \\
\hline
\end{tabular}

The data presented in the above table shows that the ranking of Asian Countries Library and Information Science distribution of $\mathrm{H}$ Index (country's number of articles (h) that have received at least $h$ citations) the China is in the first rank with $67 \mathrm{H}$ indexes followed by Taiwan and Hong Kong with $62 \mathrm{H}$ indexes respectively and Singapore is in third rank with $60 \mathrm{H}$ indexes. Also India is in fifth rank with $53 \mathrm{H}$ Indexes.

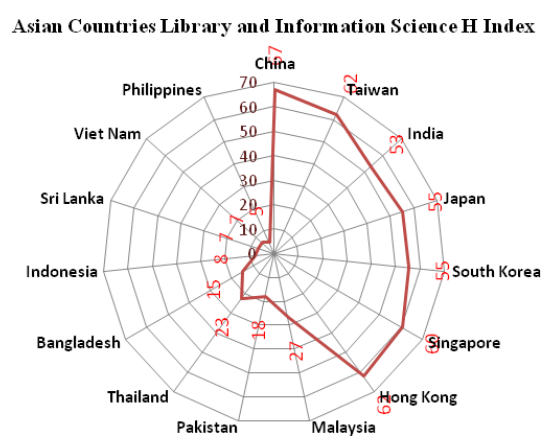

\section{CONCLUSION}

The superiority and magnitude of research are made obtainable through indexing journals with citations of various articles. There is wanting, for providing citations to other articles which authors cite. For reviewing the prior articles which are very much important for behind your article value added point for publishing. It is a good practice to give self citation for their previous works and it follows up of the previous one and improved one. During the study period from 1996 to 2016, among the 
publications, maximum of 8506 (40.06\%) articles published by China and follow ed by Taiwan with $2764(13.02 \%)$ publications and India is in $3^{\text {rd }}$

place with $2626 \quad(12.37 \%)$ publications. The present study proves that the maximum number of citable documents $8422(40.45 \%)$ by China followed by Taiwan with $2722 \quad(13.07 \%)$ and India contributed 2566(12.32\%) citable documents. The above study shows that the maximum number of citations 38816 (23.99\%) by China followed by Taiwan with 23967 (14.81\%) and India contributed $17028(10.52 \%)$ Citations. The above study reveals that maximum number of self citations 18336 (44.76\%) by China followed by Taiwan with 5504 (13.43\%) and India's self citation is 4408 (10.76\%).Among the citations per document study, Hong Kong is in first rank with 22.73 followed by Singapore with 14.15 in second rank and South Korea is in third rank with 10.50 citations per document used. The $\mathrm{H}$ Index study shows that China is in the first rank with $67 \mathrm{H}$ indexes followed by Taiwan and Hong Kong each with $62 \mathrm{H}$ indexes and Singapore is in third rank with $60 \mathrm{H}$ indexes. Also India is in fifth rank with $53 \mathrm{H}$ Indexes. It is concluded that the maximum number of Asian Countries Library and Information Science publications, Citable documents, citations, self citations are in the rank of China, Taiwan and India respectively.

\section{REFERENCES}

1.Senthilkumar. R. and G. Ulaganathan, (2017). A Scientometric analysis of astrophysics research output in India: Study based on Web of science. Asian J. Inform. Sci. Tech. 7(1): 5-13.

2.Rajneesh and M.S. Rana, (2015). Citation Analysis of Computer Science Literature. Rankings of Indian Universities: An Analysis. Int. Caliber-2015, 41-54.

3. Krishnan, V. and S. Raja, (2014). Citation Analysis on Current Science Publications: A Global Perspective. Int. J. Curr. Res. Acad. Rev. 2(1): 7687.

4.Seeman, T., P. Sivaraman and R. Sevukan, (2013). Bradford's law and the research productivity of environmental science researchers in selected universities of south India. Int. J. Lib. Inform. Sci. 2(2): 1-12.

5.Khatun, A. and S.M. Ahmed Zabed, (2011). A bibliometrical analysis of diarrheal research in Bangladesh. Ann. Lib. Inform. Stud. 58: 109-117.

6.SCImago, (2007). SJR - SCImago Journal \& Country Rank. Retrieved October $24^{\text {th }} 2017$, from http://www.scimagojr.com. 